\title{
Prevalence of communication disorders in Port Blair-Andaman and Nicobar Islands
}

\author{
Sreeraj Konadath*, Prashanth Prabhu, Vimala Jayakrishna Kasturi, Pavithra Kannan, \\ Shezeen Abdul Gafoor, Revathi Raveendran, Chandan Rajendra, Prateek Lokwani \\ All India Institute of Speech and Hearing, Manasagangothri, Mysuru, India
}

\section{A R T I C L E I N F O}

\section{Keywords:}

Prevalence

Communication disorders

Port blair andaman and nicobar islands

\begin{abstract}
A B S T R A C T
Objective: Andaman and Nicobar Islands is a union territory in the Indian sub-continent with a very diverse and large population. There was no existing data regarding the prevalence of communication disorder in this region and hence, this study was taken up. This information was considered essential for creating awareness among the population about communication impairments, for providing rehabilitation and to improve policies and facilities for the affected individuals.

Method: The study was completed in two phases. In the first phase, a door to door survey was carried out by students and staffs of All India Institute of Speech and Hearing, Mysuru, in the islands. During this phase, all individuals with communication disorders were identified and referred for a two-day camp that followed. The second phase involved diagnosis and rehabilitation of these referred individuals in a camp site set in a well accessible point in the capital city of Port Blair.

Results: $4.12 \%$ of the population that was surveyed got referred for the camp. Amongst the referred individuals who participated in the camp, the prevalence of ear-related problems was estimated to be $47.76 \%$, and that of speech and language disorders came up to $52.24 \%$. It was also noticed that males were more affected by communication disorder than females.

Conclusion: The prevalence values were found to be quite high in city of Port Blair and immediate action is required in terms of facilities and infrastructure in these areas for improving the quality of life of individuals with communication disorders.
\end{abstract}

\section{Introduction}

Communication is the process of conveying and/or receiving information through any mode from one another. It facilitates information transfer and is necessary for an individual's social and emotional well-being. The act of communication can be considered efficacious when an appropriate response is obtained from the receiver. A dissonance between need for communication and the ability to communicate can be termed as communication impairment. According to ASHA, communication disorder is "an impairment in the ability to receive, send, process and comprehend concepts or verbal, non-verbal and graphic symbol system". ${ }^{1}$ This may manifest as difficulties in hearing, language and/or speech.

For a holistic picture of the status of communication disorders, it is important to know the epidemiologic data related to it. Epidemiologic data is usually represented using incidence or prevalence rates. Prevalence is that proportion of the population with a particular characteristic at a particular point of time. Such data help professionals to plan service delivery, check the efficacy of existing rehabilitation programs, and to consider boundaries between typical and atypical development.

In 2011, World Health Organization released the World Report on Disability which gave an estimate of the prevalence of disability in selected countries in the different continents around the globe. In New Zealand (20.0); (20.0) in Australia; in the African countries like Botswana (2.2), Chad (20.9), Ethiopia (3.8), Ghana (12.8), Kenya (15.2), Malawi (14.0), Mali (9.8), Senegal (15.5), Tanzania (9.5), Uganda (3.5) and Zambia (14.8); in North American countries like Canada (18.5), United States (19.4), Mexico (2.3); in South America Brazil (14.5), Nicaragua (10.0), Ecuador (12.1), Uruguay (16.0); in

\footnotetext{
*Corresponding author. All India Institute of Speech and Hearing, Manasagangothri, Mysore, 570 006, India.

E-mail addresses: sreerajkonadath@aiishmysore.in, sreeraj.aslp@gmail.com (S. Konadath).
} 
European countries like Austria (14.4), Germany (18.4), Italy (5.0), Netherlands (11.6), Poland (10.0), United Kingdom (12.2), Spain (15.0) and Sweden (12.1); in Asian countries like Bangladesh (0.8), China (6.4) and India (2.1). ${ }^{2}$ Studies have reported hearing impairment as the most common cause of communication disability around the world. It has been expected to be present in $10 \%-60 \%$ of individuals of above 65 years of age in the United States. ${ }^{3-5}$

Being the seventh largest in the area and second most populous country with one of the most diverse population in the world, each population needs to be studied in specific to get a big picture of the disability status of the Indian Sub-continent. According to the World Health Organization 2008, around 63 million people suffer from deafness in India. ${ }^{6}$ According to the National Sample Survey Organization 2011, the population of the disabled population with hearing impairment was determined to be $19 \%, 7 \%$ with speech handicap and $6 \%$ with intellectual disability(7). There are a few area specific prevalence studies carried out within India. ${ }^{8-14}$ These studies report a high proportion of communication disorders in India when compared to the world population. Also, one can notice the difference in the proportion of the population affected per area.

A study conducted by Das et $\mathrm{al}^{8}$ in the rural districts of Kolkata, reported a high prevalence of stroke leading to communication impairments. Ganesh et al. ${ }^{9}$ and Bhagya et al. ${ }^{10}$ reported a high prevalence of mental disability in different communities of Karnataka. In a study conducted in a rural district of Karnataka by Konadath et al., ${ }^{11}$ the prevalence of communication disorders was found to be around $6.07 \%$ among the 15,441 individuals who were surveyed.

Konadath et al. ${ }^{12}$ reports a prevalence of communication disorders to be $3.63 \%$ in a group of islands in Lakshadweep, whereas, Mishra et al. ${ }^{13}$ reports it to be $15.14 \%$ in rural areas of Lucknow district in India. A survey done by Sinha et al. ${ }^{14}$ in a rural population of Gujarat reports an overall prevalence of $4.09 \%$, with a higher prevalence of earrelated communication disorders in comparison with speech and language related communication disorders.

The difference across regions could be due to a variety of reasons like lifestyle ${ }^{15}$ habits, economic status, literacy rates ${ }^{16}$, living conditions (urban vs rural), cultural differences, ${ }^{17}$ and geographical location. The data from previous studies also suggest that there is an urgent need to carry out more of such studies on a larger scale to help in contributing to the overall development of the country and the quality of life of individuals with communication disorders.

One such area, with limited access to services related to communication disorders is the Andaman and Nicobar Islands, a union territory in India. The access to healthcare facilities is limited when compared to that in the Indian mainland. The studies done in different regions of Indian mainland have indicated that there is a high prevalence of communication disorders. While, there are no studies indicating the status of communication disorders in these regions of India. Hence, the present study was taken up to find out the prevalence of the communication disorder in the capital city (Port Blair) of the Union Territory of Andaman and Nicobar Islands.

\section{Method}

According to the Census of India-2011, this group of islands are inhabited by a population of 379944 people. ${ }^{7}$ The diversity of the population is very vast and accommodates more than six languages, five religions and multiple cultures including some tribal population. The capital city, Port Blair was shown to have a population of $100186 .^{18}$ The population consists of male $52.92 \%$ (53247) and female $47.07 \%$ (47361). 9.3\% of the population is under the age of 6 .

The study was carried out in two phases. The first phase included a door to door survey of using a High-Risk Register (HRR), ${ }^{19}$ wherein individuals with communication disorders were identified. The survey was conducted in the towns of Aberdeen Bazaar, Bamboo Flat, Bathu Basti, Bunyabad, Dairy farm, Delanipur, Haado, Harbour workers colony, Junglighat, and Pani ghat. The second phase of the study included the evaluation of the identified individuals in a two-day camp held at an easy access location for the public.

\subsection{Participants}

The native residents of the Andaman Islands were surveyed in the first phase. A total population of 49495 in the city of Port Blair was included as participants of the study. The information required was collected from adults in the household. The individuals identified as 'at risk' for communication disorders identified through the use of $\mathrm{HRR}^{19}$ were selected as the participants for phase 2 of the study.

\subsection{Procedure}

Phase 1, which included the door-to-door survey, was conducted by 96 NSS volunteers, from two NSS groups of AIISH for four consecutive days. Among the NSS volunteers, there were undergraduate speech and hearing students and postgraduate students of Speech-Language Pathology or Audiology. The orientation regarding the information to be collected during the survey was given to the volunteers by the four staffs who accompanied the volunteers (who were qualified audiologists or speech-language pathologists, with at least a master's degree).

The survey was conducted to identify individuals who were at risk for communication disorders, on a question and answer basis. A general questionnaire (Appendix I) was used to identify individuals with communication disorders within each household. The questionnaire included questions regarding demographics, number of members in the house, presence of any sort of communication problem (which was further divided and subdivided as speech, language and hearing related problems), age of individuals with such problem etc. The identified individuals were then referred to the camp for further evaluation and to obtain guidelines about the management of the problem. The NSS volunteers covered a population of around 49495 on 4 days. Amongst the surveyed, 2092 individuals were given a referral to attend the camp.

Phase 2 of the study, involved the evaluation and provision of habilitation or rehabilitation of the individuals, as and how required. A two-day screening camp was carried out at Teacher's Training Centre and Teacher's Home, Port Blair. One thousand eight hundred seventynine people availed different services according to their rehabilitation need. The different sectors of rehabilitative services were distributed in and around the campsite and directions were given to the individuals by volunteers. The entry of an individual to the camp site was followed by a brief registration and collection of the referral form issued during the survey. The HRR developed at the All India Institute of Speech and Hearing ${ }^{19}$ was then administered on these individuals. It had queries about age, gender, region, socio-economic status, and educational history of the individual. The presence of any causative or risk factor like any medical and familial history was also noted.

The medical history and causative factors were divided into three segments as prenatal, natal and post-natal and were particularly administered in case of children. The prenatal history encompassed the questions about excessive vomiting (after the first trimester), elderly pregnancy (more than 35 years of age), hyper/hypotension during the gestational period, high/low blood sugar level during the gestational period, history of abortions, Rh incompatibility, viral/bacterial infections, exposure to chemical fumes, habit of alcohol consumption or smoking and intake of ototoxic medication. The natal history included 
the questions about low birth weight (less than $1.5 \mathrm{Kg}$ ), neonatal jaundice (underwent phototherapy), delayed birth cry (greater than $20 \mathrm{~s}$ ), premature delivery, birth asphyxia, fetal distress, aspiration of amniotic fluid, abnormal delivery, NICU admission and APGAR scores. Presence of craniofacial anomalies, syndromes, degenerative diseases, viral/bacterial infections, convulsions, decreased vegetative skills, history of acute/chronic suppurative otitis media (ASOM/CSOM), trauma to head/neck, cancer/tumours, cerebrovascular accidents, presence of functional/psychological disorders, voice abuse/misuse and noise exposure were enlisted in the post-natal history. The individuals were then taken to the different services arranged in the campsite such as ENT consultation, hearing evaluation, hearing aid trial, ear mould fitting, speech and language evaluation, and psychological evaluation.

The individuals who had ear-related complaints were sent for an ENT evaluation as the first step. The ENT specialist carried out a detailed case history along with an otoscopic examination. Required medications were provided to the patient in case of a conductive pathology. They were then sent for a hearing evaluation, if necessary. The audiological evaluations were carried out in a closed room, distant from major noise sources. Biological calibration was used to account for the environmental noise present. Pure tone audiometry was carried by student volunteers under the supervision of a qualified audiologist. The air conduction thresholds were measured across $0.5 \mathrm{kHz}, 1 \mathrm{kHz}, 2 \mathrm{kHz}$ and $4 \mathrm{kHz}$ and bone conduction thresholds were obtained for $1 \mathrm{kHz}$, $2 \mathrm{kHz}$ and $4 \mathrm{kHz}$ pure tones using a portable type II audiometer. The diagnosis of the degree of hearing loss was made based on Modified Classification System. ${ }^{20}$ The middle ear status of the patient was examined using immittance audiometry (tympanometry and reflexometry) with Type 3 Immittance Meter.

Once the hearing evaluation was completed, appropriate referrals were made to the patient including hearing aid trial. The patients were given a trial with a digitally programmable hearing aid. The trial was carried out by programming the aid according to the NAL-NL1 prescriptive formula. Subjective preference and opinions about comfort and audibility were also taken into account. The aid was prescribed to all individuals fitting into the criteria of hearing disability as per the RPWD Act ${ }^{21}$ and when found to be suitable for the persons' needs. The individuals were counselled about usage, maintenance and realistic expectations from the aid.

The speech and language evaluation was carried out by student volunteers under supervision. Standardized language screening tools were used to assess individuals with complaints of inadequate speech and language skills. The oro-motor examinations were carried out for individuals with speech complaints along with the administration of standardized tools for articulatory errors, voice complaints, swallowing issues, oro-motor weakness, and fluency issues. Standardized screening tools and tests such as Receptive-Expressive Emergent Language Scale, 3-Dimensional Language Acquisition Test, Stuttering Severity Instrument and Hindi Articulation Test and were used to assess the individuals. The individuals with complaints about mental abilities underwent a psychological evaluation. Vineland Social Maturity ScaleIndian adaptation and Developmental Screening Test were used for the screening of mental disorders by the Clinical Psychologist. The individuals with speech and language problems were sent for an ENT evaluation in case of maxillo/craniofacial anomalies, voice complaints, or delayed development. The queries of the individuals were answered and proper counselling was given about the intervention strategies to be used. They were also counselled about methods for generalization of the achieved responses. Home training materials were distributed for language, articulation, voice, fluency disorders after proper counselling.

\section{Results}

A total population of 49495 were surveyed in which 2092 (4.22\%) were identified to be 'at risk' for communication disorders. The HRR helped in identifying the factors (congenital, medical, familial, and genetic) which accounts for the presence of communication disorders in the individuals. Among the 2092 individuals, 1056 were referred with speech and language issues like fluency, voice, articulation, academic difficulties, maxillofacial anomalies, motor speech disorders, and language delays. While, 1036 individuals were referred with ear related problems including blocking sensation, itching, ear pain, ear discharge, reduced hearing sensitivity, and tinnitus. The gender wise prevalence of the different communication disorders identified is given in Table 1 .

The evaluation camp was held for two consecutive days for a span of $8 \mathrm{~h}$ each day; and among 2092 referred individuals, a total of 291 individuals reported at the campsite. 143 of the reported population reported having speech and language related issues, among which 78 (29\%) individuals had speech related issues and 62 (23\%) individuals had language related complaints. 148 (48\%) individuals were reported to have ear-related issues.

\subsection{Ear-related problems}

Individuals with ear-related problems were sent for an ENT checkup initially. One hundred forty-eight individuals were evaluated by ENT specialist and 128 among them were recommended for audiological evaluation. The ENT specialist evaluated 64 individuals with otalgia, 49 individuals with otorrhea, and 37 individuals with complaints of tinnitus. The occurrence of otalgia and otorrhea was found to have a higher prevalence in the paediatric age group (otalgia - 45.3\%; otorrhea - 40.8\%) followed by adult age group (otalgia - 31.2\%; otorrhea $32.6 \%$ ) and a lesser prevalence in the geriatric age group (otalgia $23.4 \%$; otorrhea - 26.5\%). The identified individuals were provided with appropriate medical services like otoscopic evaluation, clearance of ear discharge and medicines were provided to the required. The distribution of different ear-related issues among the reported individuals is being represented in Fig. 1.

As a rehabilitative measure, 60 individuals were given medications according to their need for treatment by the ENT physician. Out of the 148 individuals who presented with ear-related issues, 121 individuals were identified to have hearing loss and seven were evaluated to have normal hearing sensitivity in both ears. Out of the 121 individuals with hearing loss, seven individuals (5.7\%) had unilateral hearing loss and 114 individuals $(94.2 \%)$ were found to have bilateral hearing loss. Table 2 shows the distribution of severity of hearing loss in Port Blair.

\subsection{Speech and language disorder}

Among the 291 individuals who reported, 143 of them had problems related to speech and language skills. Three of the reported individuals were found to have clinically normal speech and language skills. $78(26.8 \%)$ of the evaluated individuals were identified with language disorders. 62 individuals of these were pediatric population (79.4\%) and 16 individuals were adults (20.5\%). Among the pediatric population with a language disorder, 16 were diagnosed with spoken language disorder (20.5\%), 25 with intellectual disability (32.05\%), 13 with hearing impairment (16.6\%) and 11 with academic difficulty (14.1\%), showing signs of learning disability. 12 were diagnosed to fall under Autism Spectrum Disorders (ASD) (15.3\%) and one child was diagnosed with attention deficit hyperactive disorder (ADHD) $(1.2 \%)$. The gender distribution of the language disorders identified is given in Fig. 2. 
Table 1

Prevalence of different types of communication disorders identified.

\begin{tabular}{|c|c|c|c|c|c|c|c|c|c|c|c|c|c|c|}
\hline & & \multicolumn{13}{|c|}{ Prevalence of Communication Disorders } \\
\hline & & \multicolumn{4}{|c|}{ Ear related } & \multicolumn{4}{|c|}{ Language } & \multicolumn{5}{|c|}{ Speech } \\
\hline & & Otal. & Otor. & Tin. & HI & SLD & ID & HI & Aca. & Voi. & Flu. & Art. & MSD & Lary. \\
\hline \multirow[t]{2}{*}{ Gender } & M & 0.30 & 0.18 & 0.10 & 0.56 & 0.25 & 0.16 & 0.27 & 0.11 & 0.11 & 0.10 & 0.12 & 0.10 & 0.004 \\
\hline & $\mathrm{F}$ & 0.33 & 0.16 & 0.04 & 0.37 & 0.22 & 0.14 & 0.12 & 0.06 & 0.05 & 0.06 & 0.09 & 0.09 & - \\
\hline
\end{tabular}

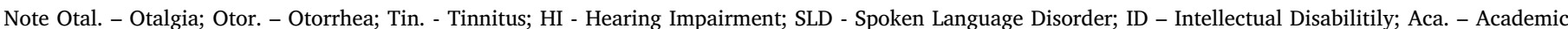

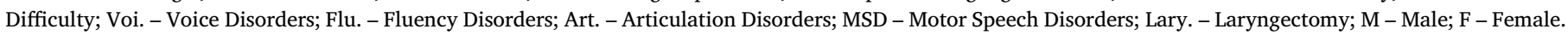

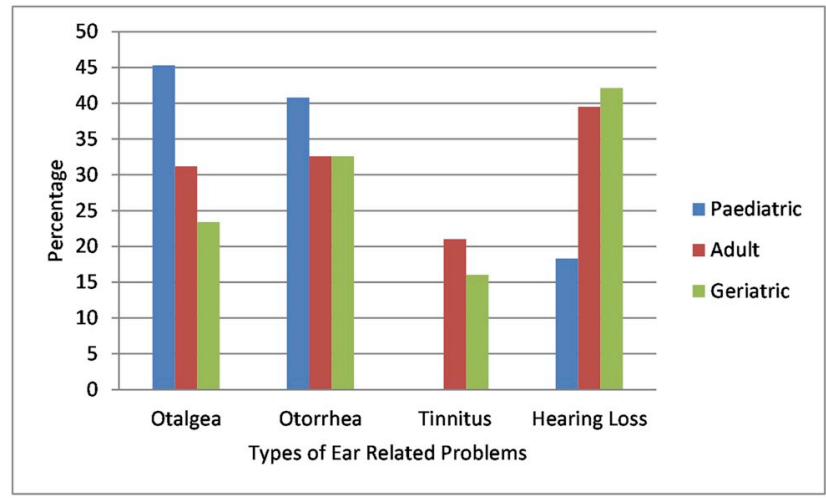

Fig. 1. Distribution of ear-related disorders evaluated in Port Blair.

Table 2

Distribution of Severity of Hearing Loss.

\begin{tabular}{lllllll}
\hline & \multicolumn{2}{l}{ Number of ears } & & & \\
\cline { 2 - 7 } & P & & A & & G & \\
\cline { 2 - 7 } & M & F & M & F & M & F \\
\hline Minimal & 6 & 2 & 2 & 2 & - & - \\
Mild & 2 & - & 12 & 18 & 20 & 10 \\
Moderate & 4 & - & 10 & 6 & 22 & 11 \\
Moderately Severe & 2 & 2 & 6 & 4 & 10 & 8 \\
Severe & 6 & 6 & 4 & 6 & 4 & 6 \\
Profound & 7 & 6 & 14 & 9 & 6 & 2 \\
\hline
\end{tabular}

Note P-Paediatric (< 15y); A-Adults (15-60y); G-Geriatric ( $>60 y$ ); M-Male; FFemale.

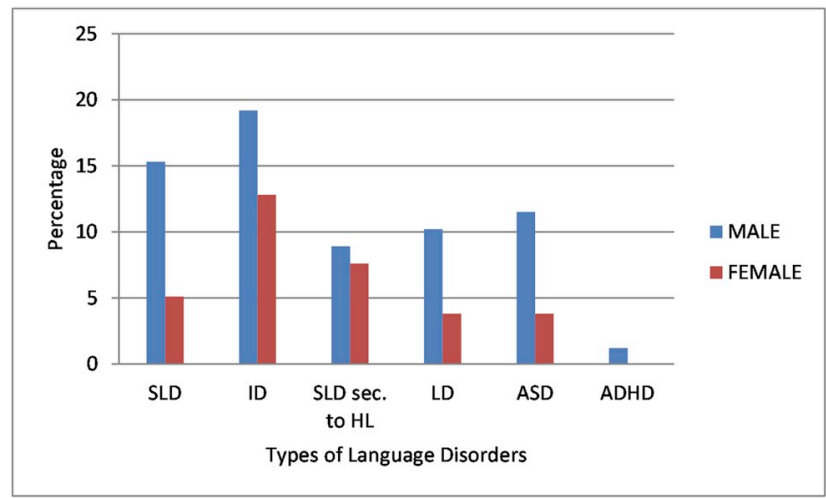

Fig. 2. Distribution of language disorders evaluated in Port Blair.

Note: SLD-Spoken Language Disorder; ID-Intellectual Disability; SLD sec. to HLSpoken Langugae Disorder secondary to Hearing Loss; ASD-Autism Spectrum Disorder; ADHD-Attention Deficit Hyperactivity Disorder.

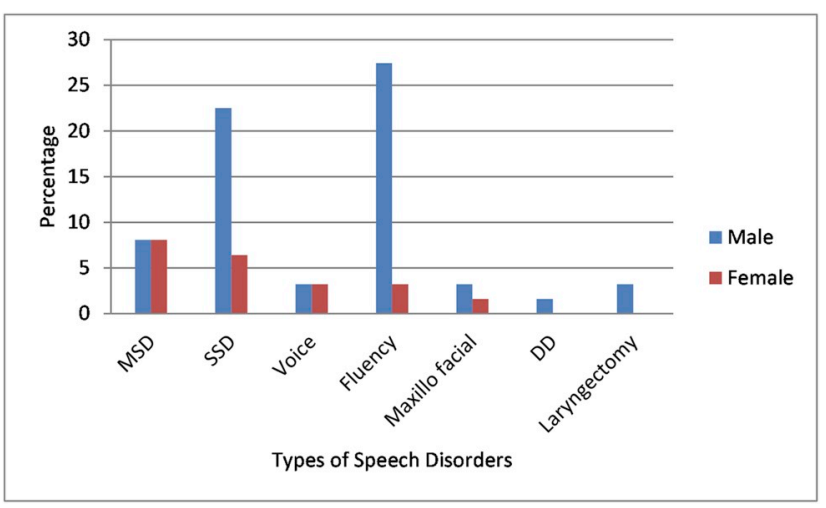

Fig. 3. Distribution of speech disorders.

Note: MSD- Motor Speech Disorder; SSD- Speech Sound Disorder; DDDevelopmental Delay.

62 individuals $(43.3 \%)$ were identified with speech disorders. The major speech disorders identified were: 4 with voice disorders $(6.4 \%)$, 19 with fluency (30.6\%), 18 with articulation disorders (29\%), 10 with motor speech disorder(16.1\%) and 3 with maxillofacial anomalies (4.8\%). 2 individuals with laryngectomy (3.2\%) who reported were evaluated for swallowing and alaryngeal speech options. Six individuals were evaluated to have multiple speech and language disorders (4.1\%). The distribution of speech disorders evaluated in Port Blair is represented in Fig. 3.

Among the 143 individuals, 126 were referred for psychological evaluation. Adequate counselling and training strategies were given to these individuals by the psychologist. The demonstrable speech therapy techniques were administered for adult and child cases in the presence of caretaker. Around 138 individuals attended demonstrative speech therapy and counselling.

\section{Discussion}

The door-to-door survey carried out by the student NSS volunteers covered a population of 49495, among which 2092 (4.22\%) were identified to be 'at risk' for communication disorder and were referred for the camp. A total of 291 individuals reported at the camp to avail the various evaluation and rehabilitation services. 143 (out of 291) were having speech and language related issues and 148 (out of 291) reported with ear-related issues. Around $49.1 \%$ were identified to have speech and language problems while $50.8 \%$ had ear-related issues.

When compared to the Indian mainland, the prevalence of communication disorders in Port Blair showed a similar prevalence rate. In their study, Konadath et al. ${ }^{11}$ revealed the prevalence of 'at-risk' population for communication disorders to be $6.07 \%$ in the rural parts of 
Karnataka, India in population size of 15441 . Sinha et al. ${ }^{14}$ surveyed a population of 28954 in the rural parts of Gujarat and found a prevalence rate of $4.09 \%$. When compared between ear-related issues and speech and language related issues, near-equal prevalence was found in Port Blair. This finding is in dissonance with those done in other areas of India, such as Lakshadweep, Karnataka, Gujarat etc. ${ }^{11,12,14}$

\subsection{Ear-related problems}

A gender wise comparison of ear-related issues revealed men to be more affected than women. This finding is on par with several other studies. ${ }^{22-25}$ One of the major factor attributed is that workspace involving noisy environment are primarily male dominant. The noise exposure during this phase may be one of the contributing factors to greater incidence of hearing loss amongst males in the current study as well. Even in participants with no noise exposure, literature reports a higher incidence of hearing loss in males when compared to females. ${ }^{25}$

Also, the majority of the individuals with hearing problems belonged to the geriatric group (as indicated in Table 2). Age-related deterioration of hearing ability has been well established over the years. ${ }^{22,25,26}$ Apart from this, studies also suggest a combination of the two factors, ageing and noise exposure, adds up and brings a more deleterious effect. ${ }^{27}$

\subsection{Speech and language problems}

The prevalence of speech and language disorders was found higher in the paediatric population than in adults, and, in males than females. A higher rate of speech sound disorder (SSD) and Fluency disorders was found. The probable reason for this could be the multiple language exposure that the children have during their language acquiring age. In their study, Hambly et al., ${ }^{28}$ reports that evidences are present for qualitative differences and production errors in children who are exposed to more than one single language. According Census of India 2011, Andaman and Nicobar islands is reported to have more than six languages spoken by its population. ${ }^{6}$ The same holds true for Port Blair with more than four languages spoken by its population. ${ }^{29}$ Many times, the need (here, multiple languages) overflows the capacity of the child and this gets manifested as speech errors. Studies have shown that the effort put forth for language dominance can result in disfluent errors which can manifest as fluency disorders. ${ }^{30}$

There was an increased prevalence of intellectual disability leading to language disorders that were found. The minimal number of rehabilitative services offers a reduced scope for primary prevention (awareness activities), secondary prevention (identification) and tertiary prevention (rehabilitative services). The unavailability of proper rehabilitative services would have been a reason for this high rate.

The prevalence of speech and language disorder was found to decrease with increase in age. Similar results were found in the literature. ${ }^{11,12,14}$ Studies also reported that as the age increases young children outgrow their communication difficulties and improve in their speech and language skills. ${ }^{31}$

\section{Summary and conclusions}

The study was carried out to find out the prevalence of communication disorders in Port Blair, Andaman and Nicobar Islands. The study was carried out in two phases which involved phaselin which a door to door survey was carried out in the different towns of Port Blair and individuals 'at risk of communication disorders' were identified. These referred individuals were asked to report at the two day camp for diagnostic and rehabilitative services. The estimated prevalence of communication disorder in the city of Port Blair was found to be $4.22 \%$. This percentage of communication disorders was found to be similar to the prevalence data obtained from the Indian mainland. The increased prevalence rate of communication disorder points out that there is an increased need for better awareness among the population on communication disorders. And thus implementing primary, secondary and tertiary prevention of communication disorders.

This study was carried out in a well-structured manner in the restricted time period that was available. Also, the survey was carried out by professionals unlike usual studies wherein, non professionals like school teachers, anganwadi workers, ASHA workers etc. are employed for the purpose. The professionals are better versed with deviations from the expected disorders (which is better suited for identifying even rare disorders or those with atypical presentations). This process also avoids unnecessary referrals (better identification of normal deviations that may be present).

However, due to time restrictions, the entire population of the capital city could not be covered, which would have given a better estimate of the prevalence. It is recommended that further studies of the kind may be carried out to provide the entire information. Also, the people of Port Blair were given preliminary strategies in terms of rehabilitation of the affected individuals (like the basic therapy techniques required for the specific disorder). Orientations were provided to them, wherein, the importance of early identification and rehabilitation of individuals with communication disorders was explained. Tips for preventing communication disorders were also provided (role of consanguineous marriage in communication disorder, exposure to toxic chemicals, loud noises etc and its impact in the long run etc.). Hence, follow up studies are required to check the efficacy of these strategies and its impact on quality of life of individuals with communication disorders and prevalence of communication disorder in that particular area.

\section{Conflicts of interest}

Authors have no conflict of interest.

\section{Acknowledgements}

Authors acknowledge the Director of All India Institutes of Speech and Hearing, Dr Pushpavathi M, for permitting to conduct this camp, providing adequate support through approvals, grants and inspiration.

Gratitude towards staffs of Sarva Shiksha Abhiyan, Andaman and Nicobar Islands and NSS office, the University of Mysore for providing the adequate amenities and other facilities to conduct the camp.

The authors also extend their gratitude towards all NSS volunteers of All India Institute of Speech and Hearing of the year 2017-18 for participating in the data collection procedures and compilation of the data. 


\section{Appendix A. Supplementary data}

Supplementary data to this article can be found online at https://doi.org/10.1016/j.cegh.2019.08.005.

\section{Appendix 1}

ALL INDIA INSTITUTE OF SPEECH AND HEARING, MYSURU - 06

GENERAL INFORMATION QUESTIONNAIRE

NSS SPECIAL CAMP, 2017- 18 HELD AT PORT BLAIR, ANDAMAN AND NICOBAR ISLANDS. SURVEY OF COMMUNICATION DISORDERS IN (Location).

Sl. No Door No. \& Head of the Family
No. of Members SPEECH \& LANGUAGE

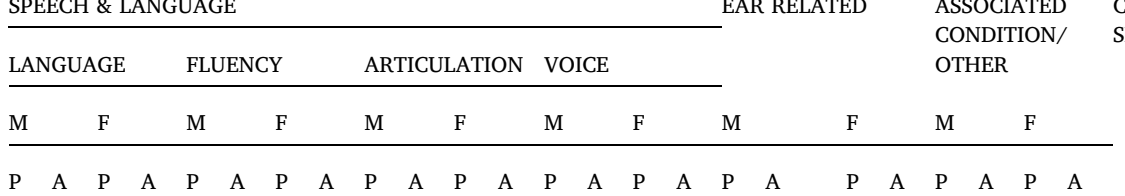

\section{References}

1. Definitions of communication disorders and variations [internet]. Asha.org. 2019; 2019. [cited 11 may 2019]. Available from: https://www.asha.org/policy/RP1993-00208/.

2. Organization WH. World Report on Disability 2011. 2011; 2011.

3. Maggi S, Minicuci N, Martini A, et al. Prevalence rates of hearing impairment and comorbid conditions in older people: the Veneto Study. J Am Geriatr Soc. 1998;46:1069-1074.

4. Campbell VA, Crews JE, Moriarty DG, Zack MM, Blackman DK. Surveillance for Sensory Impairment, Activity Limitation, and Health-Related Quality of Life Among Older Adults- United States, 1993-1997. Morbidity And Mortality Weekly Report. CDC Surveillance Summaries; 1999:131-156.

5. Reuben DB, Walsh K, Moore AA, Damesyn M, Greendale GA. Hearing loss in community-dwelling older persons: national prevalence data and identification using simple questions. J Am Geriatr Soc. 1998;46:1008-1011.

6. Organization WH. State of Hearing and Ear Care in the South East Asia Region. WHO Regional Office for South East Asia. WHO-SEARO. SEA/Deaf/92009.

7. Census2011.co.in. Literacy rate of India-population census. Accessed 05.05.19 http://www.census2011.co.in/literacy.php; 2011.

8. Das S, Biswas A, Roy T, et al. A random sample survey for prevalence of major neurological disorders in Kolkata. Indian J Med Res. 2006;124:163.

9. Ganesh K, Das A, Shashi J. Epidemiology of disability in a rural community of Karnataka. Indian J Public Health. 2008;52:125-129.

10. Bhagya B, Ramakrishna A. Prevalence of mental retardation among children in Mangalore. Nitte Univ J Health Sci. 2013;3:63

11. Konadath S, Suma C, Jayaram G, Sandeep M, Mahima G, Shreyank P. Prevalence of communication disorders in a rural population of India. J Hear Sci. 2013;3:41-49.

12. Konadath S, Chatni S, Lakshmi M, Saini JK. Prevalence of communication disorders in a group of islands in India. Clin Epidemiol Global Health. 2017;5:79-86.

13. Mishra A, Verma V, Shukla GK, Mishra SC, Dwivedi R. Prevalence of hearing impairment in the district of Lucknow, India. Indian J Public Health. 2011;55:132.

14. Sinha SK, Shivaswamy J, Barman A, Seth D, Seshadri D, Savithri S. Prevalence of communication disorders in a rural population at taluq level of Gujarat, India. Clin Epidemiol Global Health. 2017;5:73-78.

15. Ziglio E, Currie C, Rasmussen V. The WHO cross-national study of health behavior in school-aged children from 35 countries: findings from 2001-2002. J Sch Health. 2004;74:204-206.
16. Campbell TF, Dollaghan CA, Rockette HE, et al. Risk factors for speech delay of unknown origin in 3-year-old children. Child Dev. 2003;74:346-357.

17. Paniagua FA. Culture-bound syndromes, cultural variations, and psychopathology. Handbook of Multicultural Mental Health. Elsevier; 2000:139-169.

18. Chandramouli C, General R. Census of India 2011. Provisional Population Totals New Delhi: Government of India. 2011.

19. Anitha T, Yathiraj A. Modified High Risk Registers (HRR) for Professional and Nonprofessional Formulation and its Efficacy. Sp. \& Hg.); 2001 Independent Project submitted to Univ. of Mysore, as a part fulfillment of M. Sc.

20. Clark JG. Uses and abuses of hearing loss classification. Asha. 1981:23:493-500.

21. Disabilityaffairs.gov.in. 2019; 2019. [cited 10 May 2019]. Available from: http:// www.disabilityaffairs.gov.in/upload/uploadfiles/files/RPWD\%20ACT\%202016.pdf.

22. Cruickshanks KJ, Wiley TL, Tweed TS, et al. Prevalence of hearing loss in older adults in Beaver Dam, Wisconsin: the epidemiology of hearing loss study. Am J Epidemiol. 1998;148:879-886.

23. Pearson JD, Morrell CH, Gordon-Salant S, et al. Gender differences in a longitudinal study of age-associated hearing loss. J Acoust Soc Am. 1995;97:1196-1205.

24. Helzner E, Cauley J, Pratt S, Wisniewski S, Zmuda J, Talbott E. Race and sex differences in age-related hearing loss: the health, ageing and body composition study. Noise Health. 2006;8.

25. Park YH, Shin S-H, Byun SW, Kim JY. Age-and gender-related mean hearing threshold in a highly-screened population: the Korean National Health and Nutrition Examination Survey 2010-2012. PLoS One. 2016;11:e0150783.

26. Huang Q, Tang J. Age-related hearing loss or presbycusis. European Archives of Otorhino-laryngology; 2010:1179-1191.

27. Kujawa SG, Liberman MC. Acceleration of age-related hearing loss by early noise exposure: evidence of a misspent youth. J Neurosci. 2006;26:2115-2123.

28. Hambly H, Wren Y, McLeod S, Roulstone S. The influence of bilingualism on speech production: a systematic review. Int J Lang Commun Disord. 2013;48:1-24.

29. En.wikipedia.org. 2019; 2019 Port Blair. [online] Available at:. https://en.wikipedia. org/w/index.php?title $=$ Port_Blair\&oldid $=895866994$, Accessed date: 10 May 2019 .

30. Lim VP, Lincoln M, Chan YH, Onslow M. Stuttering in English-Mandarin bilingual speakers: the influence of language dominance on stuttering severity. J Speech Lang Hear Res. 2008;51:1522-1537.

31. Owens R, Metz D, Farinella K. Introduction to Communication Disorders. Pearson Education UK; 2015 